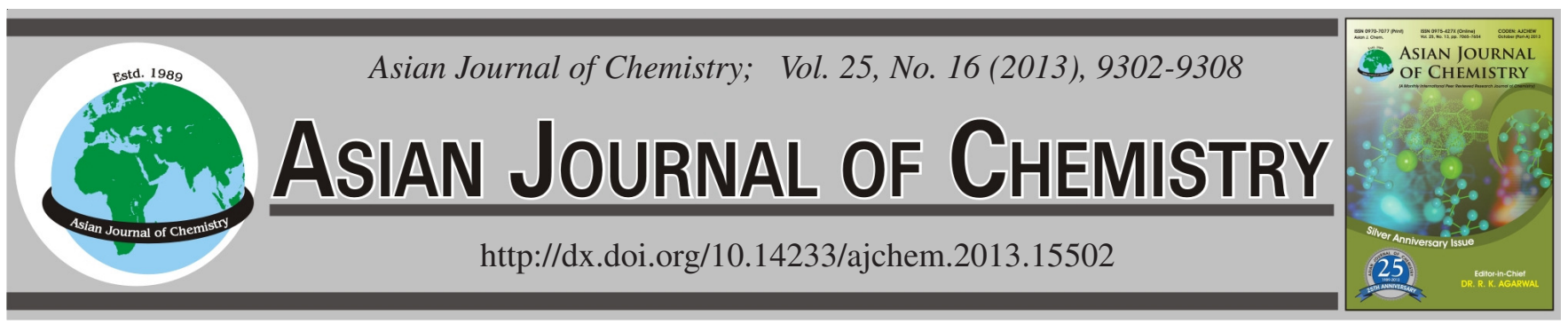

\title{
Chemical and Radiological Risks of Drinking Water from Communities in Wonderfonteinspruit Catchment, South Africa
}

\author{
Tafadzwa Marara ${ }^{1, *}$, L.G. Palamuleni ${ }^{1}$ and Eno E. Ebenso ${ }^{2}$
}

${ }^{1}$ Department of Geography and Environmental Sciences, North-West University (Mafikeng Campus), P/Bag 2046, Mmabatho 2735, South Africa ${ }^{2}$ Department of Chemistry, North-West University (Mafikeng Campus), P/Bag 2046, Mmabatho 2735, South Africa

*Corresponding author: E-mail: tafadzwa_marara@yahoo.com

\begin{abstract}
A health risk assessment was carried in the Wonderfonteinspruit catchment for the informal and formal settlements of three towns (Bekkersdal, Khutsong and Carletonville) located along the river. The aim of the study was to establish the quality of drinking water from the identified sources and determine the health risks associated using risk quotients and annual radiological absorbed dose. 12 sampling points were chosen to represent the identified drinking water sources, consisting of 6 formal and 6 informal water sources. Three water samples were collected per point and these were analyzed using ICP-MS for $\mathrm{As}, \mathrm{Cd}, \mathrm{Co}, \mathrm{Pb}, \mathrm{Zn}$ and $\mathrm{U}$ isotopes. Further calculations for risk quotients and radiological absorbed doses as well as statistical analysis were carried out using MS Excel and SPSS. Findings revealed that As and U (235 and 238) concentrations along the river were in excess of the WHO and SANS 241 (2011) guidelines, thus risk quotients in excess of 1 were recorded at various points. Statistical correlations were observed between the As concentrations and the occurrence of skin cancers as well as the $U$ concentrations and the occurrence of kidney cancer. The annual radiological absorbed dose was within the prescribed range of $0.1 \mathrm{msv} /$ year for all the age groups. These findings present serious health repercussions for the informal settlements that rely on this water for domestic consumption. A gap in knowledge surrounding the synergistic mechanisms of these metals on health poses uncertainty and warrants a baseline epidemiological study in the catchment.
\end{abstract}

Key Words: Annual radiological absorbed dose, Catchment, Informal settlements, Risk quotient.

\section{INTRODUCTION}

Development in the final lapse of the 20th century has taken a new twist that not only focuses on economic growth, but also, encompasses the aspect of environmental conservation in a new phenomenon termed 'sustainable development'. South Africa is faced with the problem of scarcity of fresh water resources and highly variable hydrological conditions leading to every major river in the country being regulated in order to ensure adequate water supply for development ${ }^{1}$. The inverse side of the water scarcity issue involves the pollution of natural water systems like rivers and streams by anthropogenic activities which include mining, industrial activities and farming.

The Wonderfonteinspruit catchment has been at the center of contemporary research in the area of water pollution as a result of mining activities. Coetzee ${ }^{2}$ reported on the airborne $\gamma$-ray scan of the upper Wonderfonteinspruit and concluded that the Wonderfonteinspruit is an important transport line of radioactive material from gold mine slime dams. Winde ${ }^{3}$ analyzed sediment and water samples from the Wonderfonteinspruit catchment and determined the presence of radio nuclides and heavy metals which were mostly trapped in the sediments and concluded that they might possibly be remobilized under certain conditions like variations in $\mathrm{pH}$, redox conditions and by re-suspension of sediments during flood events into the water column. Due to the presence of these gold deposits in the area, a great number of informal settlements have erupted in the catchment. These informal settlements lack clean water (piped water systems/potable drinking water) giving rise to utilization of untreated river water for drinking and personal hygiene in the catchment ${ }^{4}$.

A broad spectrum of effects, varying from shortness of breath to different types of cancers may occur, in the event of ingestion of drinking water containing significant amounts of trace metals ${ }^{5-8}$. The deadlier diseases like edema of the eyelids, tumor, congestion of nasal mucous membranes and pharynx, gastrointestinal, muscular, reproductive, neurological and genetic malfunctions caused by some of the metals have been documented $^{9-11}$. In other studies relating to exposure of pregnant women to relatively low concentrations of heavy metals and other industrial chemicals in drinking water results have revealed that the neural development of fetuses can be compromised resulting in the mental retardation of the offspring ${ }^{12-14}$. 
There has been little effort to establish the drinking water sources and correlations between the presence of these contaminants in water and the occurrence of the health risk associated with these contaminants amongst people living in the catchment area. Winde ${ }^{15}$ concluded that there had not been any investigation aimed at establishing possible health implications in affected communities that had been conducted in the Wonderfonteinspruit by 2006. In addition, the only health related concerns that are currently addressed by the legislation, pertain to occupational health and safety of mine workers ignoring the off-mine populations who are usually affected by pollution from upstream activities ${ }^{16}$. Therefore, the purpose and main objective of this study was to link the environmental pollution in the Wonderfonteinspruit to the human element by determining the presence of radioactive and heavy metal contaminants in the drinking water then establishing the subsequent health risks.

\section{EXPERIMENTAL}

The main methods of data collection for this study were through structured questionnaires, collection and analysis of drinking water samples from the study area. Questionnaires were administered to 160 households in the catchment to establish their drinking water sources as well as the prevalent and endemic water quality related diseases.

The Wonderfonteinspruit (WFS) river (Fig. 1) is located between latitude $28^{\circ} \mathrm{S} 53^{\prime} \mathrm{E}$ and longitude $25^{\circ} \mathrm{S} 48^{\prime} \mathrm{E}$ and runs $90 \mathrm{~km}$ from the outskirts of Johannesburg to the south west, past the towns of Krugersdorp, Bekkersdal, Carletonville and Khutsong and flows into the Mooi river near Potchefstroom. As such the townships used for this study were Bekkersdal, Khutsong and Carletonville, from where sampling points were selected taking into consideration that the Lancaster dam is the entry point and that the exit is Harry's dam and two points within the study area the Cooke attenuation dam and the Boskop dam. These points were also acting as reference points for the selection of other sampling points which were off the river, depending on the extensive use of the sources of water for domestic and other different activities.

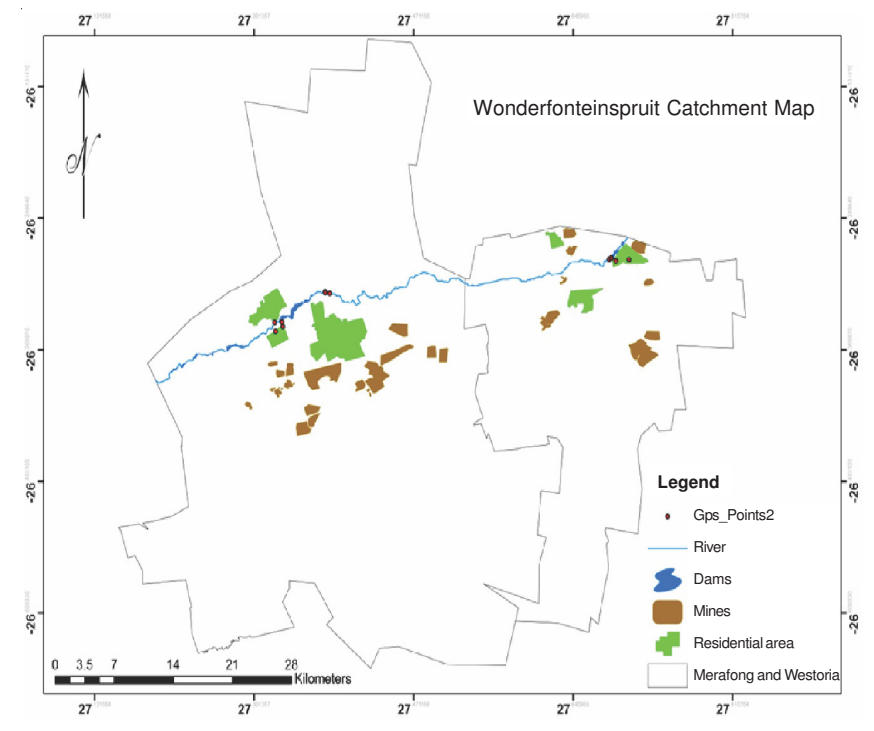

Fig. 1. Map of the study area and water sampling points
The water samples were collected in the following manner; two sets of water samples, from 12 sampling sites, were collected during the wet season (March 2012) and in the dry season (August 2012). For each sampling site, samples were collected in triplicates to increase accuracy of findings, total 72 samples. In order to ensure that the sampling points were the same, a GPS was used to record the coordinates for each sampling point. Random sampling was used to collect water samples in within the informal settlements Khutsong, Bekkersdal and Carletonville based on distance of the drinking water sources from the mines and the Wonderfonteinspruit river.

Using $1 \mathrm{~L}$ high density polyethylene bottles washed with $1 \%$ concentrated $\mathrm{HNO}_{3}$, water samples were drawn from the different identified water sources. It should also be noted that the bottles were rinsed with the sample for three times before any sample was collected. The rinsing of the bottles with the sample was done for acclimatization purposes especially for the microbial cultures. The high density polyethylene bottles are good at preservation and have a high ability of reducing contamination of the sample. In situ measurements for temperature, hydrogen potential $(\mathrm{pH})$, total dissolved solids (TDS) and electric conductivity (EC) were done using standard procedures ${ }^{17}$ by way of field meters. The information was then captured onto field data sheets. The water samples were pretreated with $3 \mathrm{~mL}$ of $\mathrm{HNO}_{3}$ for preservation purposes to avoid microbial activity. The water samples were then placed in cooler bags with ice to maintain a temperature of $4{ }^{\circ} \mathrm{C}$ and immediately transferred to Set Point Laboratories (ISO 17025 accredited) for analysis.

The water samples were analyzed for heavy metal (Co, $\mathrm{Cd}, \mathrm{Zn}, \mathrm{Pb}$ and $\mathrm{As}$ ) concentrations as well as $\mathrm{U}$ isotopes using inductively coupled plasma-mass spectrometry (ICP-MS). Calculations of radiological annual doses for uranium isotopes were done to estimate the absorbed radiation from ingestion of contaminated drinking water. The calculations were based on the following equation;

$$
\mathrm{D}=\mathrm{N} \Sigma \mathrm{n}_{\mathrm{i}} \times \mathrm{W}_{\mathrm{i}}
$$

where; $\mathrm{D}=$ radiological annual dose $(\mathrm{m} / \mathrm{Sv}), \mathrm{N}=$ the amount of water consumed in a year $(\mathrm{L}), \mathrm{W}_{\mathrm{i}}=$ the concentration of the given radioisotope $(\mathrm{Bq} / \mathrm{L}), \mathrm{n}_{\mathrm{i}}=$ Age dependent dose conversion factor $(\mathrm{mSv} / \mathrm{Bq})$ for the i-th isotope, respectively.

The dose conversion factors are defined for specific age groups and take into consideration negative influence of ingested radionuclides for the whole consumer's life. The determination of the risk quotients for all the contaminants under study was done using eqn. 2 :

$$
\text { Risk quotient }=\frac{\text { Concentration of contaminant }}{\text { Regulatory limit for contaminat ion }}
$$

The lifetime cancer risks, R, either for mortality or morbidity, associated with intake of a given radionuclide were estimated from the product of the applicable risk coefficient $r$ (mortality or morbidity) and the per capita activity intake I expressed in eqn. 3 .

$$
\mathrm{R}=\mathrm{r} \times \mathrm{I}
$$

This equation takes into consideration the activity of the radionuclide in water and the amount of water consumed the product of which is represented by $r$ and the life expectancy of the consumers (I). 
Mean and standard deviation were computed for each sampling point since the samples were collected in triplicates per site. The independent $t$-test (eqn. 4) was used to establish variations of risk seasonally and as well as according to settlement types.

$$
\mathrm{t}=\frac{\left(\overline{\mathrm{x}}_{1}-\overline{\mathrm{x}}_{2}\right)-\left(\mathrm{u}_{1}-\mathrm{u}_{2}\right)}{\mathrm{S}_{\left(\overline{\mathrm{x}}_{1}-\overline{\mathrm{x}}_{2}\right)}}
$$

The Pearson's correlation was used to establish the association between the presence of contaminants in the drinking water and the incidence of contamination related diseases.

$$
r_{x y}=\frac{\sum_{i=1}^{n}(x-\bar{x})-(y-\bar{y})}{\sum_{i=1}^{n} \Sigma_{i=1}^{n}(x-\bar{x})-(y-\bar{y})}
$$

$r_{x y}=$ correlation coefficient of two variables, $\Sigma X_{i}, \Sigma Y_{i}=$ sum of individuals.

\section{RESULTS AND DISCUSSION}

Arsenic: Arsenic concentrations in water are determined by various complex, geochemical, chemical and biochemical reactions. Its solubility is largely dependent on the $\mathrm{pH}$ where it becomes more soluble with an increase in $\mathrm{pH}$. Arsenic tends not to migrate over long distances thus its distribution in water tends to be localized around the source of pollution. This is attributed to the strong affinity of oxide minerals for As under mildly neutral to acidic conditions. Table- 1 shows results of arsenic concentrations from the study area at the various sampling points during the wet and dry seasons.

TABLE-1a

MEAN AND STANDARD DEVIATION VALUES FOR ARSENIC

\begin{tabular}{ccc}
\hline & \multicolumn{2}{c}{ Arsenic $(\mu \mathrm{g} / \mathrm{L})$} \\
\cline { 2 - 3 } & Wet season & Dry season \\
\hline Khutsong informal pt 1 & $8.2 \pm 0.13$ & $10.8 \pm 1.2$ \\
Khutsong informal pt 2 & $7.9 \pm 0.06$ & $12 \pm 3.4$ \\
Khutsong formal pt1 & $0.7 \pm 0.09$ & $0.5 \pm 0$ \\
Carletonville informal pt 1 & $14.2 \pm 0.06$ & $16.2 \pm 0.55$ \\
Carletonville informal pt 2 & $14.9 \pm 0.2$ & $14.3 \pm 0.15$ \\
Carletonville Jojo tank 1 & $0.5 \pm 0.04$ & $0.5 \pm 0$ \\
Carletonville Jojo tank 2 & $0.6 \pm 0.01$ & $0.5 \pm 0$ \\
Carletonville formal pt 1 & $0.6 \pm 0.01$ & $0.49 \pm 0.001$ \\
Bekkersdal informal pt 1 & $11.6 \pm 0.4$ & $9.6 \pm 0.4$ \\
Bekkersdal informal pt 2 & $12 \pm 0.2$ & $4.3 \pm 0.4$ \\
Bekkersdal standpipe 1 & $0.65 \pm 0.03$ & $0.5 \pm 0$ \\
Bekkersdal formal & $0.7 \pm 0.01$ & $0.5 \pm 0$ \\
\hline \multicolumn{3}{c}{ Guidelines $(\mu \mathrm{g} / \mathrm{L})$} \\
\hline SANS 241 \\
WHO(2011) & 10 \\
\hline
\end{tabular}

The concentrations of arsenic were high along the river compared to the formal water sources for both the dry and wet seasons recording 16.17 and $14.93 \mu \mathrm{g} / \mathrm{L}$, respectively, compared to the formal water sources which had a maximum of $0.67 \mu \mathrm{g} / \mathrm{L}$ (wet) and $0.49 \mu \mathrm{g} / \mathrm{L}$ (dry). Several points along the river were observed to be exceeding WHO and SANS (241) 2011standards in Carletonville, Khutsong and Bekkersdal. Noticeable were the relatively higher arsenic concentrations for the formal water sources during the wet season compared to the dry season. However, the trend was completely opposite for informal water sources where arsenic concentrations were higher during the dry season.

To determine the risk emanating from the recorded arsenic concentrations in drinking water, a risk quotient was calculated against the maximum allowable risk of 1 (Fig. 2). The trend depicts association between high concentrations in excess of the standards and the maximum risk allowed.

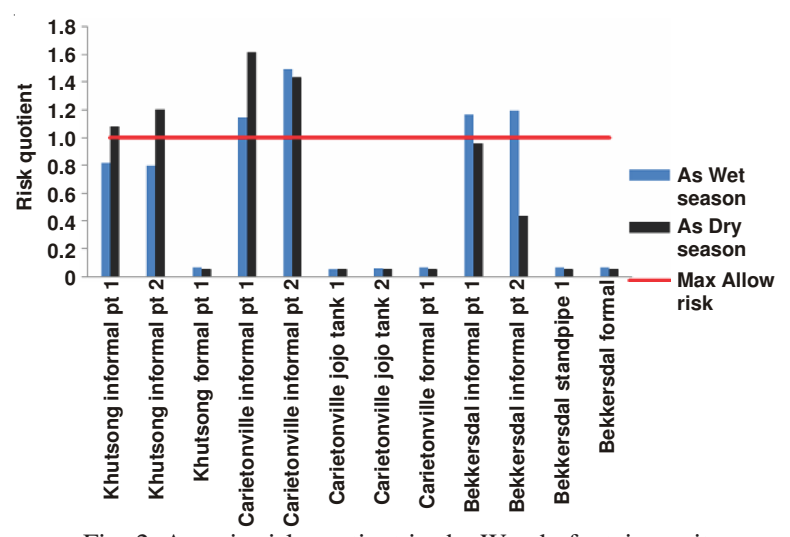

Fig. 2. Arsenic risk quotient in the Wonderfonteinspruit

The highest risk quotient for arsenic was recorded along the river in Carletonville (1.6) and the least in carletonville formal (0.05). All points along the river were above the maximum allowable risk quotient 1 . The risk quotient for arsenic follows the same pattern as the concentrations, very high along the river and negligible in the formal water sources. In terms of seasonal variation of the risk, the plot suggests that for informal water sources, such as in Carletonville, consumption of water poses a significant health risk from As both during the dry and wet seasons (1.18-1.6). Whilst in Khutsong, the health risk from As is high during the dry season for Bekkersdal it is high during the wet season. Formal water sources have a minimal risk quotient during both seasons suggesting they are safe for consumption during both periods.

Using Pearson's correlation coefficient, an association was observed $(\mathrm{R}=0.564, p<0.05)$ between the arsenic concentrations observed during the wet season and the occurrence of skin lesions. A slightly stronger association $(\mathrm{R}=0.681, p<$ 0.05 ) was observed for arsenic concentrations in the dry season. Similarly, evidence of risk of skin lesions from arsenic exposure in drinking water at concentrations less than $50 \mu \mathrm{g} / \mathrm{L}$ were reported in a longitudinal health study in Bangladesh ${ }^{18}$. Arsenic concentrations in the range of $8.1-40 \mu \mathrm{g} / \mathrm{L}$ were associated with adjusted prevalence odds ratios of skin lesions of 1.91 at $95 \%$ confidence intervals. Ahsan et al.$^{18}$ noted that the risk of skin lesions was also influenced by the body mass index (BMI), where the risk of skin lesions was inversely proportional to the BMI, which is reflective of the nutritional status. On the contrary, in another study in West Bengal India, on arsenic concentrations in groundwater and its impacts on health, a majority of the people under study did not exhibit any skin lesions but their hair and blood samples contained elevated levels of arsenic suggesting that they were sub-clinically affected ${ }^{19}$.

Table- $1 \mathrm{~b}$ shows the distribution of skin lesions with gender. There are variations in the risk of skin lesions based on gender, where $59 \%$ of the people who had suffered skin lesions were women as compared to $49 \%$ for men. Correspondingly, 
TABLE-1b

CROSS TABULATION OF SKIN LESIONS AND GENDER

\begin{tabular}{llcc}
\hline \multirow{2}{*}{ Gender } & \multicolumn{2}{c}{ Suffered skin lesions } \\
\cline { 3 - 4 } & & Yes & No \\
\hline \multirow{2}{*}{ Male } & Count & 20 & 54 \\
& Within suffered skin lesions (\%) & 41 & 47.8 \\
\hline \multirow{2}{*}{ Female } & Count & 27 & 59 \\
& Within suffered skin lesions (\%) & 59 & 52.2 \\
\hline
\end{tabular}

Haque et al..$^{20}$ observed high prevalence in women relative to men. This was attributed to low privilege and poor malnutrition and the fact that usually women are more involved in household activities, thus more exposed to the contaminated water. The Wonderfonteinspruit catchment has been described to be rife with acute malnutrition and has been dubbed the HIV capital of South Africa ${ }^{21}$ hence consumption of water contaminated with arsenic exacerbates the risk of developing skin lesions.

Uranium (U): Uranium is one of the hazardous substances that evoke two different and totally unrelated effects, one due to its radioactivity and the other due to its chemical nature. It has a low specific radioactivity and an extremely long halflife of 4.5 billion years. In this study, only two isotopes of $U$ were determined $U^{235}$ and $U^{238}$. Results of their mean concentrations are shown in Table-2.

The chemical concentrations of both $\mathrm{U}^{235}$ and $\mathrm{U}^{238}$ followed the same trend as arsenic, high along the river and very low in the formal water sources. The highest concentration for $\mathrm{U}^{235}$ and $\mathrm{U}^{238}$ being 62.3 and $59.9 \mu \mathrm{g} / \mathrm{L}$, respectively and the lowest being 0.2 and $<0.2 \mu \mathrm{g} / \mathrm{L}$, respectively. Along the river in Khutsong, both isotopes were very high in the dry season and falling within the standards during the wet season. In Carletonville along the river, both isotopes recorded high concentrations throughout the dry and wet seasons (ranging between 51 and $59.9 \mu \mathrm{g} / \mathrm{L}$ ). In Bekkersdal, all the points were in excess of the standards with the highest $U$ isotope concentrations observed during the dry season relative to the wet season. These high values along the river could be attributed to the discharge of acidic mine water.

The magnitude of chemical effects that $U$ has on the health of the Wonderfonteinspruit catchment communities, computation of the risk quotient was done for $\mathrm{U}^{235}$ and $\mathrm{U}^{238}$ (Figs. 3 and 4). An independent $t$-test was carried out to determine whether the risk was more significant in either of the seasons.

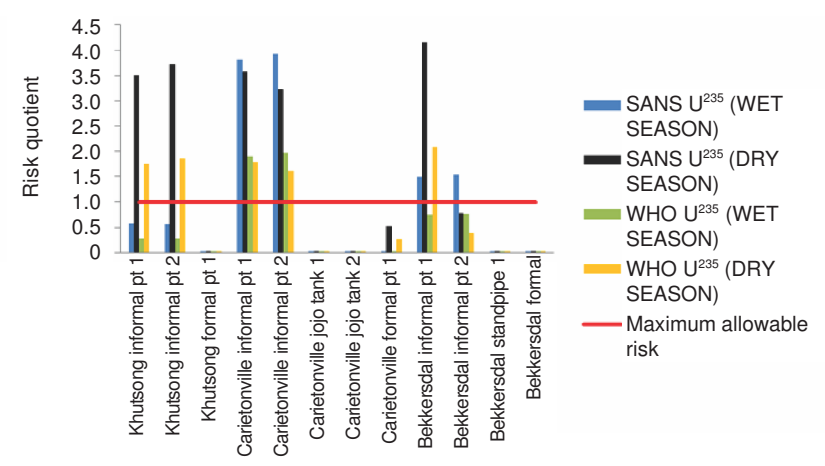

Fig. 3. $\mathrm{U}^{235}$ risk quotient in the Wonderfonteinspruit

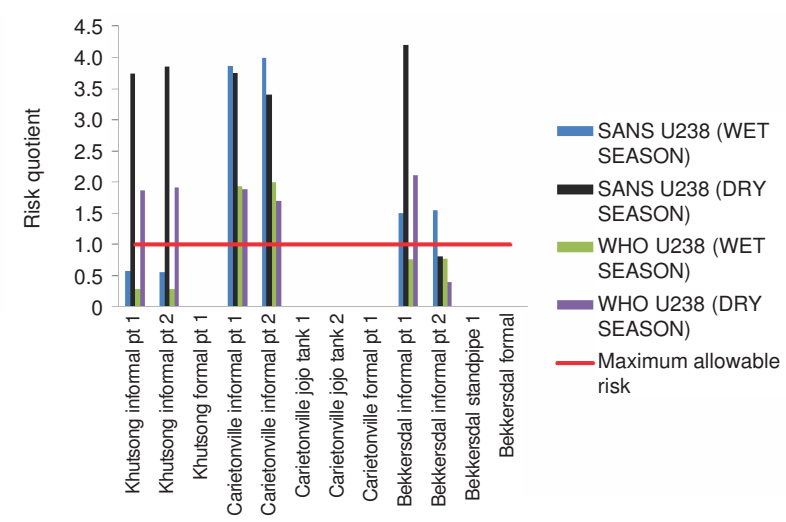

Fig. 4 . $\mathrm{U}^{238}$ risk quotient in the Wonderfonteinspruit

Results revealed no statistically significant difference between the mean concentrations for $\mathrm{U}^{235}$ isotopes in the two seasons at $95 \%$ confidence interval $(t=0.319)$. In this study, the insignificant difference in $U$ concentrations which were slightly higher in the dry season could be attributed to the fact that during the wet season there were rainfall events, which caused the dilution of the concentrated pollutants or possibly the fact that, the stormy rainfall events which occurred during the dry season, could have caused the resuspension of sediments thereby reintroducing pollutants in the water column. On the contrary, there was a statistically significant difference in the concentrations for $\mathrm{U}^{235}$ between the formal and informal

\begin{tabular}{|c|c|c|c|c|}
\hline \multicolumn{5}{|c|}{$\begin{array}{c}\text { TABLE-2 } \\
\text { ND STANDARD DEVIATION VALUES FOR URANIUM }\end{array}$} \\
\hline & \multicolumn{2}{|c|}{$\operatorname{Uranium}^{235}(\mu \mathrm{g} / \mathrm{L})$} & \multicolumn{2}{|c|}{$\operatorname{Uranium}^{238}(\mu \mathrm{g} / \mathrm{L})$} \\
\hline & Wet season & Dry season & Wet season & Dry season \\
\hline Khutsong informal pt 1 & $8.5 \pm 0.2$ & $52.7 \pm 0.6$ & $8.483 \pm 0.18$ & $56 \pm 0$ \\
\hline Khutsong informal pt 2 & $8.3 \pm 0.2$ & $56 \pm 9.6$ & $8.4 \pm 0.46$ & $57.7 \pm 7.2$ \\
\hline Khutsong formal pt1 & $0.2 \pm 0.005$ & $0.3 \pm 0.1$ & $<0.2 \pm 0$ & $0.3 \pm 0.05$ \\
\hline Carletonville informal pt 1 & $51.2 \pm 1.4$ & $53.7 \pm 2.1$ & $57.9 \pm 1.51$ & $56.3 \pm 2.5$ \\
\hline Carletonville informal pt 2 & $59 \pm 1.5$ & $48.3 \pm 0.6$ & $59.9 \pm 0.7$ & $51 \pm 1$ \\
\hline Carletonville Jojo tank 1 & $0.2 \pm 0.006$ & $0.3 \pm 0.02$ & $0.22 \pm 0.01$ & $0.28 \pm 0.03$ \\
\hline Carletonville Jojo tank 2 & $0.2 \pm 0.005$ & $0.31 \pm 0.08$ & $<0.2 \pm 0$ & $0.26 \pm 0.01$ \\
\hline Carletonville formal pt 1 & $0.2 \pm 0.005$ & $7.8 \pm 13.14$ & $0.207 \pm 0.012$ & $0.21 \pm 0.021$ \\
\hline Bekkersdal informal pt 1 & $22.4 \pm 0.056$ & $62.3 \pm 1.16$ & $22.6 \pm 1.06$ & $63 \pm 1$ \\
\hline Bekkersdal informal pt 2 & $23.1 \pm 0.5$ & $11.7 \pm 0.55$ & $23.2 \pm 0.61$ & 12. \pm 0.67 \\
\hline Bekkersdal standpipe 1 & $0.2 \pm 0.006$ & $0.277 \pm 0.04$ & $0.27 \pm 0.02$ & $0.3 \pm 0.012$ \\
\hline Bekkersdal formal & $0.2 \pm 0.006$ & $0.25 \pm 0.05$ & $0.2 \pm 0.02$ & $0.24 \pm 0.04$ \\
\hline \multicolumn{5}{|c|}{ Guidelines $(\mu \mathrm{g} / \mathrm{L})$} \\
\hline \multirow{2}{*}{\multicolumn{2}{|c|}{$\begin{array}{l}\text { SANS } 241 \\
\text { WHO (2011) }\end{array}$}} & & 15 & \\
\hline & & & 30 & \\
\hline
\end{tabular}


settlements $(\mathrm{t}=0)$ at a $95 \%$ confidence interval. Results suggest that informal settlements are at a higher risk of consuming water contaminated by $\mathrm{U}^{235}$ this is supported by the high risk which was in excess of the maximum allowable risk recorded for all informal settlements compared to the very low values for formal settlements.

An independent $t$-test was also carried out to determine whether the risk from $\mathrm{U}^{238}$ was more significant in either of the seasons. The results similar to those of $U^{235}$ revealed no statistically significant difference between the mean concentrations for both isotopes in the two seasons at $95 \%$ confidence interval $(t=0.365)$. There was also a statistically significant difference in the concentrations for $\mathrm{U}^{238}$ between the formal and informal settlements $(t=0)$ at a $95 \%$ confidence interval suggesting that informal settlements are at a higher risk of consuming water contaminated by $\mathrm{U}^{238}$. At many formal settlements, the risk was 0 suggesting that there is no chemical risk from $\mathrm{U}^{238}$ either in the wet or dry season.

Calculation of radiological annual doses was used to estimate the absorbed radiation from ingestion of contaminated drinking water. By definition, radiological annual dose is the annual dose rate caused by absorption of natural radioactive elements in water, based on the assumption that a man drinks $\mathrm{N}$ litres per year using eqn. 1 as stated in the WHO drinking water guidelines (1998). Fig. 5 shows the calculated annual radiological dose for $\mathrm{U}^{235}$ in the Wonderfonteinspruit during the wet season sampling.

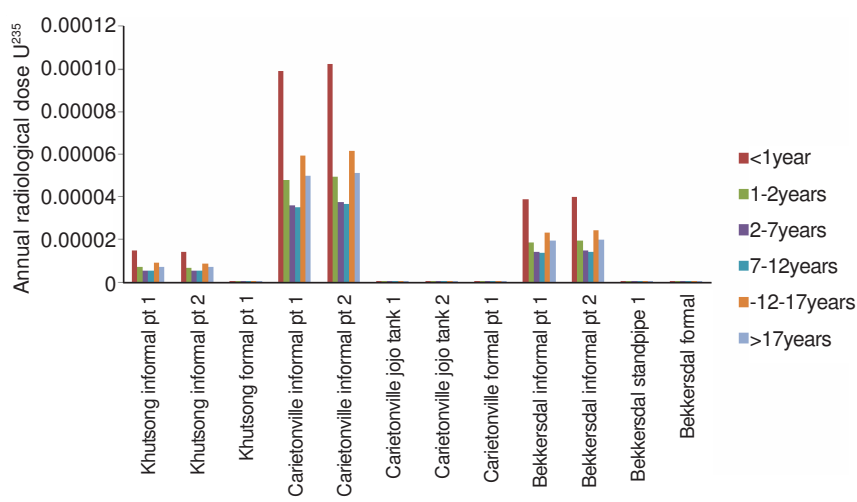

Fig. 5. Annual radiological dose for $\mathrm{U}^{235}$ in Wonderfonteinspruit (wet season)

The highest recorded radiological dose for $\mathrm{U}^{235}$ during the wet seasonwas observed in Carletonville along the river $(9.92$ $\times 10^{-5} \mathrm{mSv} / \mathrm{yr}$ ) and this was for the category of less than a year. The lowest observed was in Khutsong formal and Carletonville Jojo tank which both recorded $1.23 \times 10^{-7} \mathrm{mSv} / \mathrm{yr}$ for the category of 7-12 years.

During the dry season, the radiological absorbed dose for $\mathrm{U}^{235}$ the maximum was observed in Bekkersdal $\left(1.062 \times 10^{-4}\right.$ mSv/yr) for the category of <1year (Fig. 6) and it should be noted that compared to the wet season the radiological absorbed dose at all points along the river for infants ( $<1$ year) was higher in the dry season. The least observed during the dry season was from Carletonville jojo tank which recorded $1.19 \times 10^{-7} \mathrm{mSv} / \mathrm{yr}$ for the category of $<1$ year. All the sampling points were within the WHO 2011 and SANS 241(2011) standard which is pegged at $0.1 \mathrm{mSv} / \mathrm{yr}$ for $\mathrm{U}^{235}$ for both seasons.

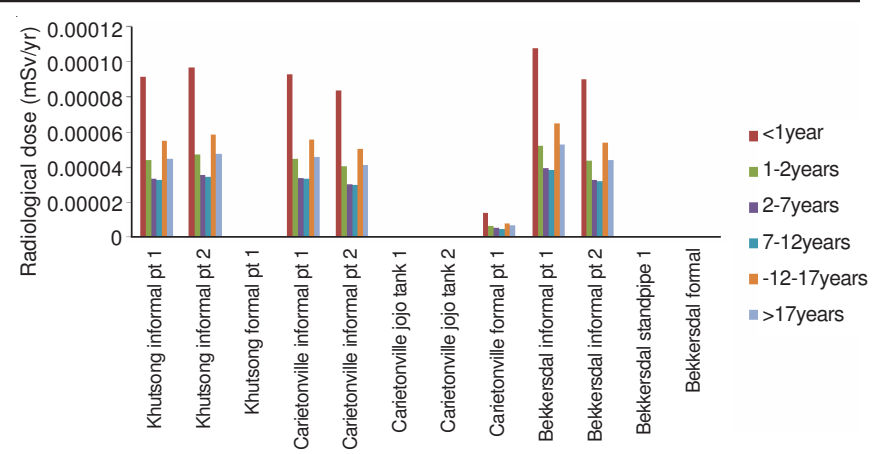

Fig. 6. Annual radiological absorbed dose $\mathrm{U}^{235}$ in Wonderfonteinspruit (dry season)

The highest recorded radiological dose for $\mathrm{U}^{238}$ during the wet season was observed in Carletonville along the river (1.01 $\times 10^{-4} \mathrm{mSv} / \mathrm{yr}$ ) and this was for the category of $<1$ year. The lowest observed was in a Carletonville jojo tank, which recorded $1.18 \times 10^{-7} \mathrm{mSv} / \mathrm{yr}$ for the category of 7-12 years (Fig. 7). For the dry season the radiological absorbed dose for $\mathrm{U}^{238}$ was at its highest in Bekkersdal $\left(1.06 \times 10^{-4} \mathrm{mSv} / \mathrm{yr}\right)$ this was for the category of <1year (Fig. 8). The least observed dose for $\mathrm{U}^{238}$ during the dry season was from Carletonville tap water which recorded $1.279 \times 10^{-7} \mathrm{mSv} / \mathrm{yr}$ for the category of $<1$ year. All the sampling points were within the WHO 2011 and SANS 241(2011) standard which is pegged at $0.1 \mathrm{mSv} / \mathrm{yr}$ for $\mathrm{U}^{235}$ for both seasons. These results imply that the age group of $<1$ year are at the highest risk of contracting diseases arising from the consumption of $U$ contaminated water like, kidney and lung inflammation ${ }^{22,23}$, since they recorded the highest dose in both seasons, but it suffices to mention that although the dose was well within the standards, Busby and Schnug ${ }^{24}$ reported increases in infant leukemia from low dose exposure to uranium.

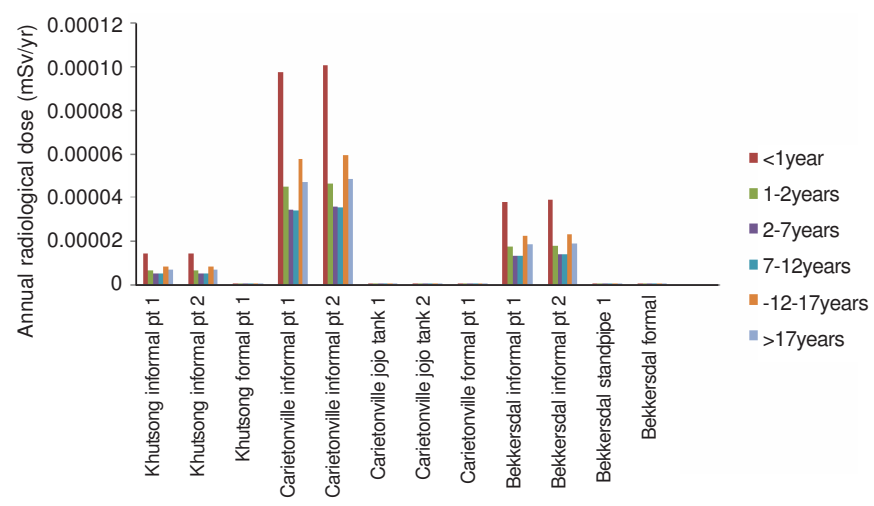

Fig. 7. Annual radiological dose $U^{238}$ (wet season)

Similarly, other authors analyzed radioactivity in bottled mineral water in Greece. Results revealed that the contribution of $U$ to the internal exposure of adults from the consumption of mineral water with the maximum determined activity was $0.77 \times 10^{-3} \mathrm{mSv} / \mathrm{yr}$. This value increased by a factor of 2.7 , $1.8,1.5$ and 1.5 for the age groups of 1-2, 2-7, 7-12 and 1217, respectively. Comparable findings were obtained by Zamora et ll $^{25}$ from a study in an aboriginal community in Australia. The highest dose of uranium calculated was $2.1 \mathrm{mSv}$ and this was the cumulative dose over a 15 -year period. The study concluded that the risk of cancer was 13 in 100000 which 
was insignificant for the population size studied meaning that chemical toxicity would be a greater health concern than the radiation dose. Based on the annual dose concentrations for $\mathrm{U}^{235}$ and $\mathrm{U}^{238}$ from the current study, similar conclusions can be drawn (Figs. 5-8).

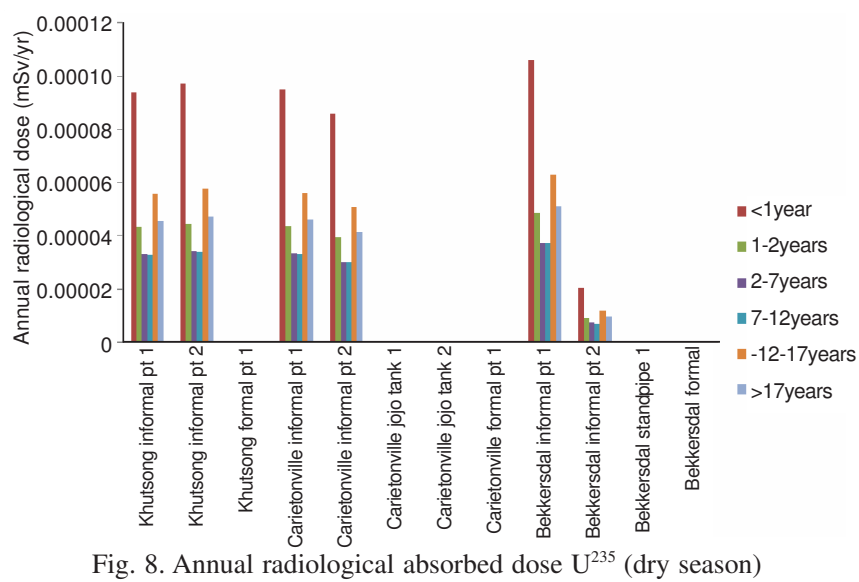

Cancer risk: In order to determine whether there is a significant risk from radiation properties of uranium a life time cancer risk for mortality and morbidity was computed based on uranium activity in water for both seasons using eqn. 3 . Table- 3 shows the cancer mortality and morbidity for $\mathrm{U}^{235}$ and $\mathrm{U}^{238}$ during the wet season.

Results indicate that during the wet season, highest cancer mortality risk is from $\mathrm{U}^{235}$ that was $6.19 \times 10^{-5}$ noted in Carletonville along the river and least from $\mathrm{U}^{238}\left(2.73 \times 10^{-7}\right)$ observed for Bekkersdal standpipes. Whilst the cancer morbidity risk was the highest for $\mathrm{U}^{235}$ in Carletonville informal settlements and the least was for $\mathrm{U}^{238}$ for Carletonville Jojo tanks.

The cancer mortality and morbidity risk for $\mathrm{U}^{235}$ and $\mathrm{U}^{238}$ during the dry season was generally higher relative to the wet season (Table-4).

During the dry season, highest cancer mortality risk was from $U^{235}$ that was $6.74 \times 10^{-5}$ noted in Bekkersdal along the river and least from $\mathrm{U}^{238}\left(2.43 \times 10^{-7}\right)$ observed for Bekkersdal tap water samples. Conversely, the cancer morbidity risk was the highest for $\mathrm{U}^{235}\left(1.04 \times 10^{-4}\right)$ in Bekkersdal along the river and the least was for $\mathrm{U}^{238}$ for Carletonville tap water $(3.35 \times$ $\left.10^{-7}\right)$. Based on another reported study, the results reflect no significant radiological risk from both isotopes of uranium in the Wonderfonteinspruit during the wet and dry seasons, since all the values recorded are lower than $10^{-3}$. Similar findings were observed in a study on the chemical and radiological risk assessment of uranium in borehole water in Nigeria ${ }^{26}$ with the magnitude of radiological cancer risks in range of $10^{-4}$.

In addition, an association was observed between the occurrence of kidney problems and the average $\mathrm{U}^{235}$ and $\mathrm{U}^{238}$ for the two seasons using Pearson's correlation coefficient ( $\mathrm{r}=$ 0.68 and 0.69 , respectively, $p<0.001$ ). These findings only serve to confirm the conclusion reported by Amakom and $\mathrm{Jibiri}^{26}$, that the chemical properties of uranium are more likely to cause health effects compared to radiological in the Wonderfonteinspruit catchment.

\section{Conclusion}

The quality of water from the informal water sources in particular river water, is not in compliance with the SANS

TABLE-3

\begin{tabular}{lcccc}
\multicolumn{5}{c}{ TABLE-3 } \\
& CANCER MORTALITY AND MORBIDITY FOR U ${ }^{235}$ AND U U $^{238}$ (WET SEASON) & \\
\hline & Cancer mortality risk U ${ }^{235}$ & Cancer mortality risk U23 & Cancer morbidity risk U $^{235}$ & Cancer morbidity risk U $^{238}$ \\
\hline Khutsong informal pt 1 & $9.23 \times 10^{-6}$ & $8.57 \times 10^{-6}$ & $1.43 \times 10^{-5}$ & $1.31 \times 10^{-5}$ \\
Khutsong informal pt 2 & $8.94 \times 10^{-6}$ & $8.51 \times 10^{-6}$ & $1.39 \times 10^{-5}$ & $1.30 \times 10^{-5}$ \\
Khutsong formal pt 1 & $2.16 \times 10^{-7}$ & $2.02 \times 10^{-7}$ & $3.36 \times 10^{-7}$ & $3.10 \times 10^{-7}$ \\
Carletonville informal pt 1 & $6.19 \times 10^{-5}$ & $5.85 \times 10^{-5}$ & $9.61 \times 10^{-5}$ & $8.96 \times 10^{-5}$ \\
Carletonville informal pt 2 & $6.39 \times 10^{-5}$ & $6.05 \times 10^{-5}$ & $9.92 \times 10^{-5}$ & $9.27 \times 10^{-5}$ \\
Carletonville jojo tank 1 & $2.49 \times 10^{-7}$ & $2.22 \times 10^{-7}$ & $3.87 \times 10^{-7}$ & $3.40 \times 10^{-7}$ \\
Carletonville jojo tank 2 & $2.16 \times 10^{-7}$ & $2.02 \times 10^{-7}$ & $3.36 \times 10^{-7}$ & $3.10 \times 10^{-7}$ \\
Carletonville formal pt 1 & $2.20 \times 10^{-7}$ & $2.09 \times 10^{-7}$ & $3.41 \times 10^{-7}$ & $3.20 \times 10^{-7}$ \\
Bekkersdal informal pt 1 & $2.42 \times 10^{-5}$ & $2.28 \times 10^{-5}$ & $3.77 \times 10^{-5}$ & $3.50 \times 10^{-5}$ \\
Bekkersdal informal pt 2 & $2.50 \times 10^{-5}$ & $2.34 \times 10^{-5}$ & $3.88 \times 10^{-5}$ & $3.58 \times 10^{-5}$ \\
Bekkersdal standpipe 1 & $2.67 \times 10^{-7}$ & $2.73 \times 10^{-7}$ & $4.15 \times 10^{-7}$ & $4.17 \times 10^{-7}$ \\
Bekkersdal formal & $2.46 \times 10^{-7}$ & $2.36 \times 10^{-7}$ & $3.82 \times 10^{-7}$ & $3.61 \times 10^{-7}$ \\
\hline
\end{tabular}

TABLE-4

CANCER MORTALITY AND MORBIDITY FOR U ${ }^{235}$ AND U ${ }^{238}$ (DRY SEASON)

\begin{tabular}{|c|c|c|c|c|}
\hline & Cancer mortality risk $\mathrm{U}^{235}$ & Cancer mortality risk $U^{238}$ & Cancer morbidity risk $\mathrm{U}^{235}$ & Cancer morbidity risk $\mathrm{U}^{238}$ \\
\hline Khutsong informal pt 1 & $5.70 \times 10^{-5}$ & $5.65 \times 10^{-5}$ & $8.85 \times 10^{-5}$ & $8.64 \times 10^{-5}$ \\
\hline Khutsong informal pt 2 & $6.06 \times 10^{-5}$ & $5.83 \times 10^{-5}$ & $9.41 \times 10^{-5}$ & $8.92 \times 10^{-5}$ \\
\hline Khutsong formal pt 1 & $3.57 \times 10^{-7}$ & $3.10 \times 10^{-7}$ & $5.55 \times 10^{-7}$ & $4.74 \times 10^{-7}$ \\
\hline Carletonville informal pt 1 & $5.81 \times 10^{-5}$ & $5.69 \times 10^{-5}$ & $9.02 \times 10^{-5}$ & $8.71 \times 10^{-5}$ \\
\hline Carletonville informal pt 2 & $5.23 \times 10^{-5}$ & $5.15 \times 10^{-5}$ & $8.12 \times 10^{-5}$ & $7.89 \times 10^{-5}$ \\
\hline Carletonville jojo tank 1 & $2.99 \times 10^{-7}$ & $2.83 \times 10^{-7}$ & $4.65 \times 10^{-7}$ & $4.33 \times 10^{-7}$ \\
\hline Carletonville jojo tank 2 & $3.35 \times 10^{-7}$ & $2.63 \times 10^{-7}$ & $5.21 \times 10^{-7}$ & $4.02 \times 10^{-7}$ \\
\hline Carletonville formal pt 1 & $8.48 \times 10^{-6}$ & $2.19 \times 10^{-7}$ & $1.32 \times 10^{-5}$ & $3.35 \times 10^{-7}$ \\
\hline Bekkersdal informal pt 1 & $6.74 \times 10^{-5}$ & $6.37 \times 10^{-5}$ & $1.04 \times 10^{-4}$ & $9.75 \times 10^{-5}$ \\
\hline Bekkersdal informal pt 2 & $5.63 \times 10^{-5}$ & $1.22 \times 10^{-5}$ & $8.75 \times 10^{-5}$ & $1.86 \times 10^{-5}$ \\
\hline Bekkersdal standpipe 1 & $2.99 \times 10^{-7}$ & $2.69 \times 10^{-7}$ & $4.65 \times 10^{-7}$ & $4.13 \times 10^{-7}$ \\
\hline Bekkersdal formal & $2.71 \times 10^{-7}$ & $2.43 \times 10^{-7}$ & $4.20 \times 10^{-7}$ & $3.71 \times 10^{-7}$ \\
\hline
\end{tabular}


241 and WHO 2011 for arsenic and uranium and as such, informal settlements of Carletonville, Bekkersdal and Khutsong are at risk of serious health problems. The elements of concern in terms of health are arsenic and $U^{235}$ and $U^{238}$ which are very high along the river and in excess of the standards. Significant health effects from uranium are likely to arise from its chemical properties rather than its radiological properties or the synergistic effect of the two. Since no statistically significant seasonal variability was observed, it can be concluded that those consuming water along the river, are equally at risk of contracting water related diseases in both the dry and wet seasons.

\section{REFERENCES}

1. NSER (National State Of The Environment Report), South Africa, Fresh water system and resources. Available at http://www.ngo.grida.no/soesa/ nsoer/issues/water/refer.htm (Accessed 15 July 2010) (1999).

2. H. Coetzee, In eds.: B.J. Merkel, S. Hurst, E.P. Löhnert and W.S. Meier Radioactivity and the Leakage of Radioactive Waste Associated with Witwatersrand Gold and Uranium Mining, Proceedings on Uranium Mining and Hydrogeology. Freiberg, Germany: Koln (1995).

3. F. Winde, Jenaer Geographische Schriften, 9, 111 (2000).

4. T. Marara, L. Palamuleni and E. Ebenso, J. Soc. Sci., 29, 73 (2011).

5. K.P. Cantor, Cancer Causes Control, 8, 292 (2007).

6. R.S. Barwick, D.A. Levy, G.F. Craun, M.J. Beach and R.L. Calderon, CDC Surveillance Summaries, 491 (2000).

7. Y. Xia and J. Liu, Toxicology, 198, 25 (2004).

8. M. Dogan, A. Dogan, C. Celebi and Y. Baris, Indoor Built Environ., 14, 533 (2005).

9. F. Johnson, Mutat. Res./Rev. Mutat. Res., 410, 123 (1998).
10. L. Tsuji and J. Karagatzides, Bull. Environ. Contamin. Toxicol., 67, 489 (2001).

11. S. Abbasi, N. Abbasi and R. Soni, Heavy Metal in the Environment, Mittal Publication, New Delhi, India, edn. 1 (1998).

12. P. Grandjean and K. Murata, Epidemiology, 18, 25 (2007).

13. P. Grandjean and P.J. Landrigan, Lancet, 368, 2167 (2006)

14. D.C. Bellinger, K.M. Stiles and H.L. Needleman, Pediatrics, 90, 855 (1992).

15. F. Winde, Phys. Geogr., 27, 379 (2006).

16. R.A. Adler, M. Claassen, L. Godfrey and A.R. Turton, Econ. Peace Security J., 2, 32 (2007).

17. H.F. Hemond and E.J. Fechner-Levy, Chemical Fate and Ransport in the Environment, C.A. San Diego, Academic Press, edn. 2 (2000).

18. H. Ahsan, Y. Chen, F. Parvez, L. Zablotska, M. Argos, I. Hussain, H. Momotaj, D. Levy, Z. Cheng, and V. Slavkovich, Am. J. Epidemiol., 163, 1138 (2006)

19. D. Chakraborti, M.M. Rahman, K. Paul, U.K. Chowdhury, M.K. Sengupta, D. Lodh, C.R. Chanda, K.C. Saha and S.C. Mukherjee, Talanta, 58, 3 (2002).

20. R. Haque, D. Mazumder, S. Samanta, N. Ghosh, D. Kalman, M.M. Smith, S. Mitra, A. Santra, S. Lahiri and S. Das, Epidemiology, 14, 174 (2003).

21. J.E. Stoch and F. In Winde, Water SA, 36, 239 (2010).

22. R. Zaire, M. Notter, W. Riedel and E. Thiel, Radiat. Res., 147, 579 (1997).

23. H. Schroeder, A. Heimers, R. Frentzel-Beyme, A. Schott and W. Hoffmann, Radiat. Protect. Dosimetry, 103, 211 (2003).

24. C. Busby and E. Schnug, In eds.: L.J. De Kok and E. Schnugg, Advanced Biochemical and Biophysical Aspects of Uranium Contamination, Loads and Fate of Fertilizer Derived Uranium, Leiden, Netherlands: Backhuys Publishers (2007).

25. M.L.L. Zamora, J.M. Zielinski, G.B. Moodie, R.A.F. Falcomer, W.C. Hunt and K. Capello, Arch. Environ. Occup. Health, 64, 228 (2009).

26. C. Amakom and N. Jibiri, Int. J. Phys. Sci., 5, 1009 (2010). 